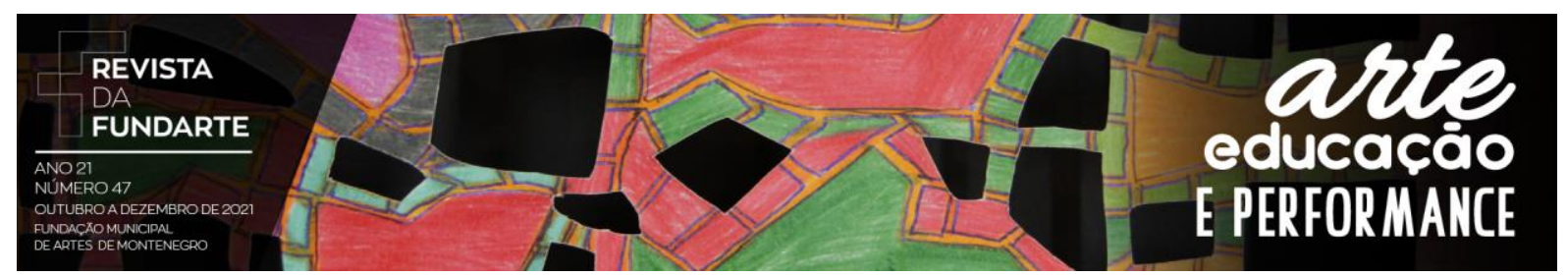

\title{
MATRIZES TEÓRICAS SOBRE O DESENHO DE CRIANÇAS E ADOLESCENTES: CONTRADIÇÕES À VISTA
}

Priscila Anversa

Gustavo Eger Sawada

\begin{abstract}
Resumo: Este texto pretende colocar em debate as matrizes teóricas do desenho de crianças e adolescentes a partir de uma experiência na disciplina de Desenho Infantil, do curso de Licenciatura em Artes Visuais da Universidade do Estado de Santa Catarina (UDESC). Objetivamos analisar desenhos a partir de estudo de caso, fruto da disciplina em questão, buscando problematizar o referencial teórico sobre a temática a partir dos autores presentes no plano de ensino, evidenciando também a necessidade de ampliar estudos na área. Para tecer a crítica, partiremos de Duarte (2001, 2010), Derisso (2010) e Mesquita (2010), enquanto para contextualizar o desenho infantil e o estudo de caso, utilizaremos Mèredieu (2006) e Lowenfeld e Brittain (1977).
\end{abstract}

Palavras-chave: Desenho Infantil; Desenho do adolescente; Ensino de Arte.

\section{THEORETICAL MATRICES ON CHILDREN'S AND TEENAGER'S DRAWING: CONTRADICTIONS AHEAD}

\begin{abstract}
This text intends to debate the theoretical matrices of children's and adolescent's drawing from an experience in the subject of Children's Drawing, from the Degree in Visual Arts at the University of the State of Santa Catarina (UDESC). We aim to analyze drawings from a case study, result of the discipline in question, seeking to problematize the theoretical framework on the subject from the authors present in the teaching plan, also highlighting the need to expand studies in the area. To weave the criticism, we will start with Duarte (2001, 2010), Derisso (2010) and Mesquita (2010), while to contextualize children's drawing and the case study, we will use Mèredieu (2006) and Lowenfeld and Brittain (1977).
\end{abstract}

Keywords: Children's Drawing; Teenager's Drawing; Art Education.

\section{Introdução}

Este texto parte de questionamentos levantados na disciplina de Desenho Infantil ocorrida na segunda fase do curso de Licenciatura em Artes Visuais da UDESC. Por meio dos estudos de autores presentes na bibliografia, como Lowenfeld e Brittain (1977), Luquet (1969) e Mèredieu (2006), algumas interrogações passaram a povoar as aulas, sobretudo no que concerne à atualização das pesquisas em 


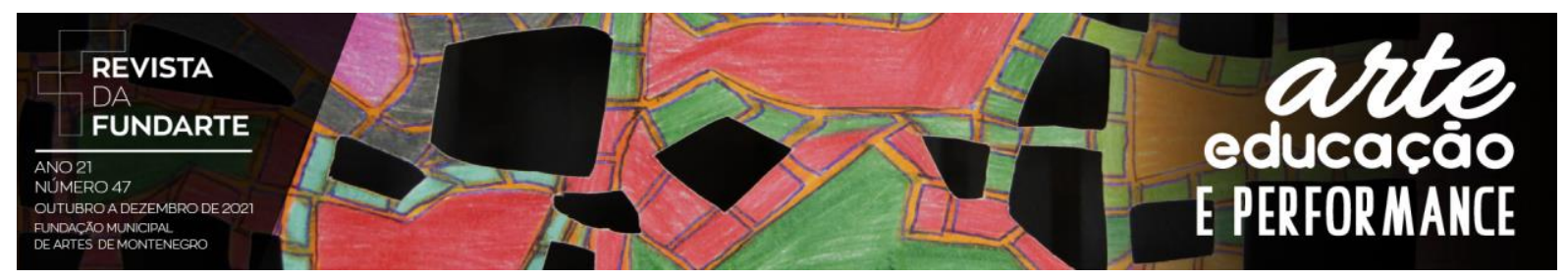

desenho, uma vez que suas teses são centrais na disciplina e nas produções acadêmicas que discutem os processos de desenho na infância e adolescência.

Evidenciamos que a esfera dos estudos do desenho infantil é marcada por teorias que partem de compreensões naturalizantes e espontaneístas do desenvolvimento, e que, precisamente por isso, é necessário problematizar o desenvolvimento humano contido nessas concepções. Através da ementa e dos debates realizados durante as aulas, surgiram indagações que circundaram não somente elas como também são manifestadas no presente artigo: Como analisar os desenhos das crianças e adolescentes conforme tais teorias? Quais são as matrizes filosóficas dos autores que discutem o desenho infantil?

Partindo dessas perguntas, o texto se concentra em examinar os desenhos de uma criança de nove anos através dos autores abordados na disciplina e discorrer sobre os aspectos presentes nas matrizes filosóficas desses, de forma a apontar suas contradições e refletir sobre elas. Assim, o estudo buscará debater no tópico um $O$ que dizem os autores sobre o desenho do pré-adolescente e do adolescente, as principais ideias dos autores presentes no plano da disciplina, colocando em discussão as teses de Luquet, Mèredieu e Lowenfeld e Brittain. Em $A$ experiência em analisar dados a partir de um estudo de caso elucidaremos a complexidade de examinar os desenhos de adolescentes à luz das teorias evidenciadas, salientando a enorme lacuna em investigar os desenhos sob uma perspectiva que não considera os múltiplos determinantes e que compreende o desenvolvimento como um processo natural. Já As contradições do referencial teórico sobre o desenho infantil, discutirá as matrizes filosóficas dos pensadores do desenho infantil, pontuando as complexidades advindas desses, encerrando a discussão e encaminhando aos desdobramentos finais desse texto.

\section{O que dizem os autores sobre o desenho do pré-adolescente e do adolescente}

Em um primeiro momento, é necessário definir a adolescência, para então nos aprofundarmos nos autores que categorizam o desenho neste período de transição entre a infância e a vida adulta. A Organização Mundial da Saúde (OMS) 


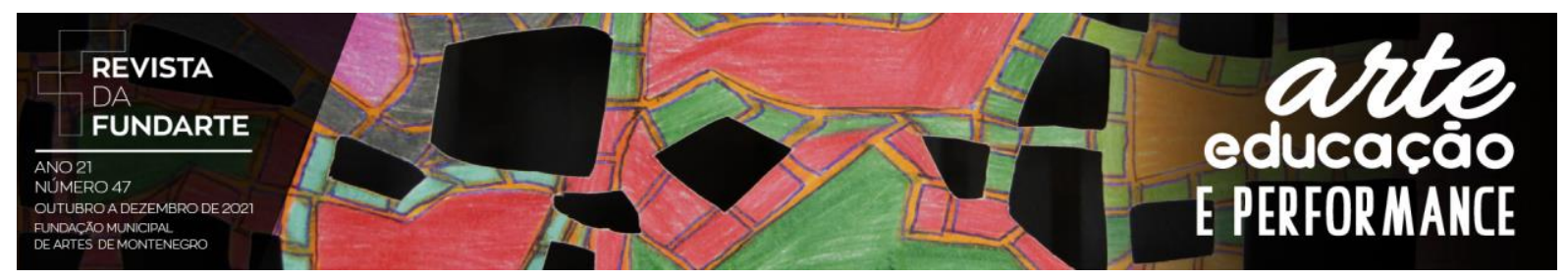

compreende a adolescência entre dez e dezenove anos, definição adotada como marcador referencial pelo Ministério da Saúde brasileiro. A OMS declara ainda que tal fase não é composta por um grupo homogêneo, variando com o sexo, estágio de desenvolvimento, condições de vida e socioeconômicas do seu ambiente. Dessa forma, nos ateremos a analisar os autores que especificam o desenho da infância, com enfoque nas fases que compreendem idades superiores aos dez anos. $O$ primeiro deles é Georges-Henri Luquet, o qual em seu livro "O Desenho Infantil" (1969) estabelece fases da evolução do desenho infantil, que, advindas do desenho involuntário, se diferenciam pelo modo como a criança articula a intenção realista. Para este autor o realismo é uma característica constante do desenho infantil que evidencia a capacidade de observação da criança. As faixas etárias não se encontram explicitadas nas fases, bem como a fase do Realismo Visual não possui um capítulo exclusivo.

Conforme Luquet, o Realismo Intelectual inicia por volta dos quatro anos, e não é incomum se estender até a vida adulta, fazendo parte também do repertório das produções de adolescentes. É característica marcante dessa fase o desenho ser representado de modo que todos os elementos reais do objeto apareçam, mesmo que invisíveis. É comum a utilização da transparência, do uso de legendas (mesmo daqueles que não saibam escrever), a não sobreposição e o rebatimento. No Realismo Visual, Luquet (1969) destaca o fim do período do desenho infantil. Sua principal característica é a submissão à perspectiva. $O$ autor aborda também a narração gráfica e sua importância na transição entre as duas últimas fases, sendo marcada também pela substituição da narração do tipo sucessivo pelo tipo epinal, ou seja, da mesma forma em que a criança tende a substituir as formas de narração, ela também o faz com sua representação do real. A narração do tipo simbólico, utilizada tanto por adultos como por crianças, não ocorre até os onze ou doze anos, onde se representa um dos diferentes momentos da ação, considerado o mais importante.

Outro autor que também compreende o desenho por fases é Jean Piaget, definindo três etapas que descrevem uma evolução do espaço dentro das representações infantis, tendo seu ápice na utilização da perspectiva - questão 


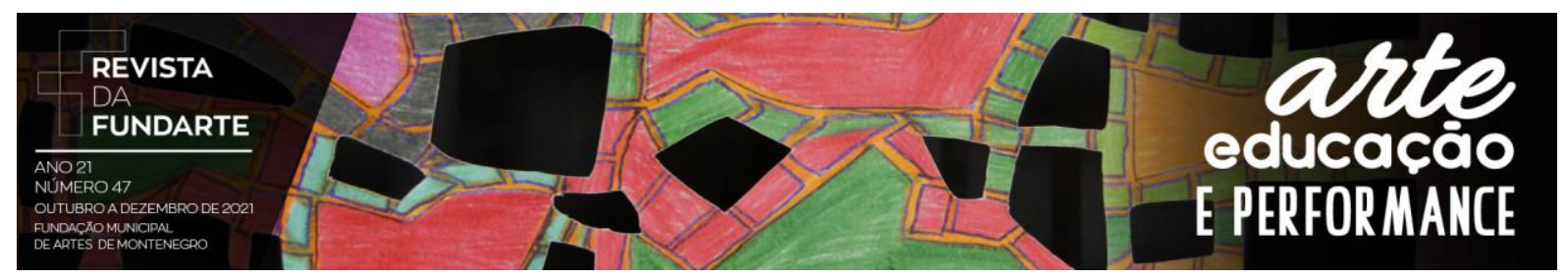

problematizada por Mèredieu (2006) - e que, em aspectos essenciais, correspondem aos estágios definidos por Luquet. Dentro dessas fases, o realismo visual é a única que contempla a idade especificada para nossa análise do estudo de caso. O Realismo Visual, segundo Mèredieu (2006), tem seu início entre oito e nove anos de idade e marca uma preocupação em respeitar as proporções das figuras. Aparece a perspectiva, questionada pela autora se é uma parte inevitável do desenvolvimento do desenho infantil ou resultado de um condicionamento sócioeducativo de uma sociedade, afirmando se tratar de uma análise do desenho de uma infância ocidentalizada.

Lowenfeld e Brittain (1977) demarcam três fases que contemplam a faixa etária de dez a dezenove anos: a Idade da Turma, a Fase Pseudonaturalista e $O$ período da decisão. Os autores definem não apenas as características do desenho de cada etapa, como também transformações no desenvolvimento da criança, suas relações com outros indivíduos e com a sociedade e as questões particulares de cada estágio com o ensino de Arte. A ldade da Turma é a fase que se inicia aos nove anos, estendendo-se aos doze. Seu nome se dá pela recém introdução da criança à sociedade, iniciando um crescente progresso da independência social e do domínio adulto. A criança começa então a andar em grupos/turmas que geralmente são do mesmo sexo ${ }^{1}$. Começam também a se questionar sobre a sociedade e sobre o próprio ser. Tornam-se mais críticas sobre si e sobre os outros, e algumas começam a esconder seus desenhos dos adultos ou fazerem comentários depreciativos de suas produções (LOWENFELD E BRITTAIN, 1977).

Quando olhamos para os desenhos dessa fase percebemos, segundo os autores acima mencionados, o abandono do esquema e a vontade de representar características que distinguem os sexos. Os desenhos não são consequência de uma observação visual, mas sim de ideias preestabelecidas daquilo a ser desenhado. Existe um maior preciosismo quanto aos detalhes, e por consequência uma perda do sentido da ação, gerando maior rigidez e formalismo nos desenhos. Não existem ainda tentativas de demonstrar luz e sombra, movimento ou dobras em

1 Lowenfeld e Brittain utilizam a palavra sexo sem distinção entre sexo e gênero. No tópico 2 utilizamos a palavra gênero, pois compreendemos que a as "características sexuais" expressas nos desenhos são em si parte das concepções e dos papeis sociais de gênero na contemporaneidade. 


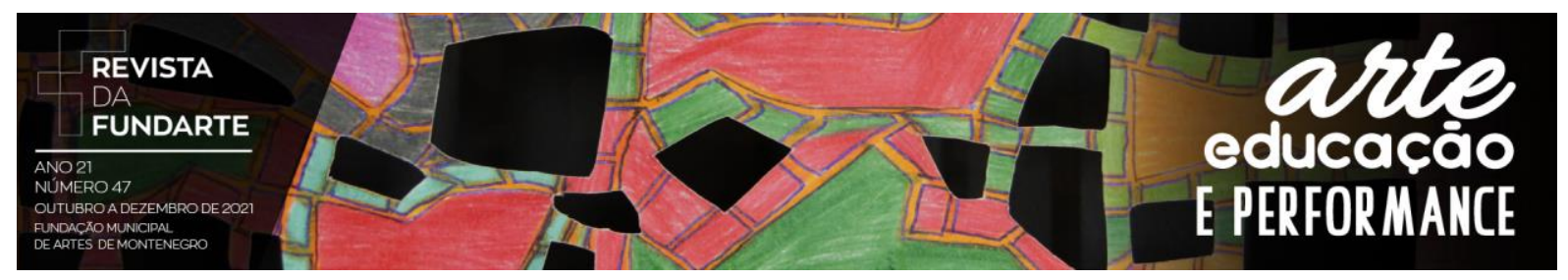

roupas. Existe, no entanto, uma mudança na representação do espaço, transformando a linha de base em uma representação mais naturalista, com um preenchimento nos espaços entre linhas de base (chão/céu). O uso da cor se torna mais consciente de variações tonais.

A Fase Pseudonaturalista inicia aos doze anos e se estende até os catorze. Para Lowenfeld e Brittain (1977), essa fazse marca o fim do desenho como atividade espontânea e o início do período de raciocínio, com uma maior criticidade perante suas produções. É notável também uma grande variedade na produção artística dos jovens dessa etapa.

A superação da ldade da Turma se dá pelo surgimento da luz e sombra, representação de pregas e movimento nas roupas, representação de articulações nos membros, tridimensionalidade e ilusão de profundidade. Por conta das mudanças físicas, características sexuais exageradas também se fazem presentes. Para alguns jovens, as caricaturas e os desenhos de humor se tornam mais atrativos. O adolescente adquire um sentido intuitivo da cor e do traçado e a relutância com a arte também se aprofunda.

No Período da Decisão - fase que tem seu início aos catorze anos e dura até os dezessete - o jovem mais amadurecido descobre uma nova independência e busca sua identidade, ao passo que se torna consciente do mundo adulto e das responsabilidades que o aguardam num futuro próximo. Esta etapa marca também o início da arte intencional e deliberada para aqueles que a mantêm como uma prática já que, muitos dos jovens, param de considerar a arte parte da sua vida. $\mathrm{O}$ fazer artístico se torna um esforço consciente e as preocupações do jovem com a sociedade, normas e costumes estipulados pelas gerações anteriores podem ser um combustível para essa produção artística. Ainda assim, vê uma discrepância entre o que produz e o que considera apropriado para um adulto.

A análise de Mèredieu (2006) sobre autores como Luquet e Piaget demonstram uma insuficiência da parte deles em elucidar e classificar, em totalidade, o desenho da criança. Apesar de não especificar o desenho do adolescente, a autora traz reflexões sobre a influência dos mass media (mídia de massa), que mesmo antes do advento da internet, afetam a produção da infância. 


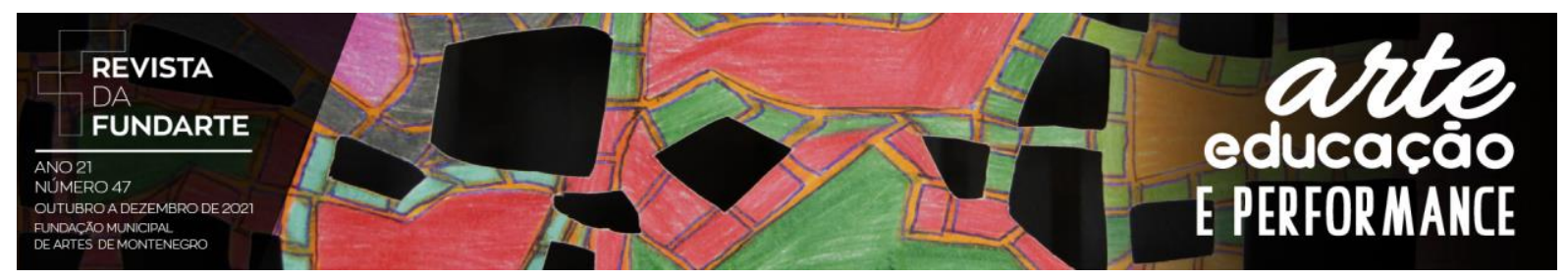

Para Mèredieu (2006), Luquet foi o primeiro autor a distinguir as fases do desenho infantil e ao tecer a crítica, a autora apresenta as quatro fases do desenho infantil deste autor, as quais carregam em seu título o termo "realismo", considerando-o uma progressão do grafismo infantil como um objetivo a ser alcançado. A autora sublinha a falta de explicações na transição entre fases e sobre o porquê de o desenho tender a desaparecer, concluindo, portanto, o hiato na terminologia adotada por Luquet.

Sobre a influência da mídia de massa, Mèredieu (2006) elucida que a "cultura pobre" - forma como ela denomina as imagens da publicidade, cinema, televisão e revistas, em contraste à "cultura tradicional" - age mais profundamente na criança em relação ao adulto. Dessa forma, as produções infantis estão sob influência dos mass media, e tal influência não deve ser deixada de lado ou julgada com desprezo pelas instituições de ensino.

A autora afirma ainda que "o desenho infantil reflete também o acontecimento, a atualidade" (MĖREDIEU, 2006, p. 111), sendo que as referências ao atual se dão de diferentes formas para cada fase da infância. Até os cinco anos a influência de seu período quase não aparece, já que o repertório dessa fase é basicamente os temas infantis. É a partir dos cinco anos - com a escolarização, leitura e um maior conhecimento social - que tal repertório se expande e o desenho da criança se torna o eco das realidades sociais intrínsecas de sua cultura.

As concepções explicitadas fornecem incipiente base teórica para se defrontar à realidade, para examinar os dados presentes nos desenhos coletados, uma vez que evidenciamos que tais referenciais teóricos possuem incongruências. Além do mais, analisar os desenhos a partir dos teóricos apresentados não desobriga a crítica, e, neste sentido, discordamos de concepções que naturalizam o desenvolvimento do grafismo, pois o consideramos como processo sócio-histórico. Concernente à investigação, abordaremos a seguir como foi possível analisar os dados através do aporte teórico elucidado neste tópico 1 , indicando pistas das contradições teóricas e colocando-as em debate.

\section{A experiência em analisar dados a partir de um estudo de caso}




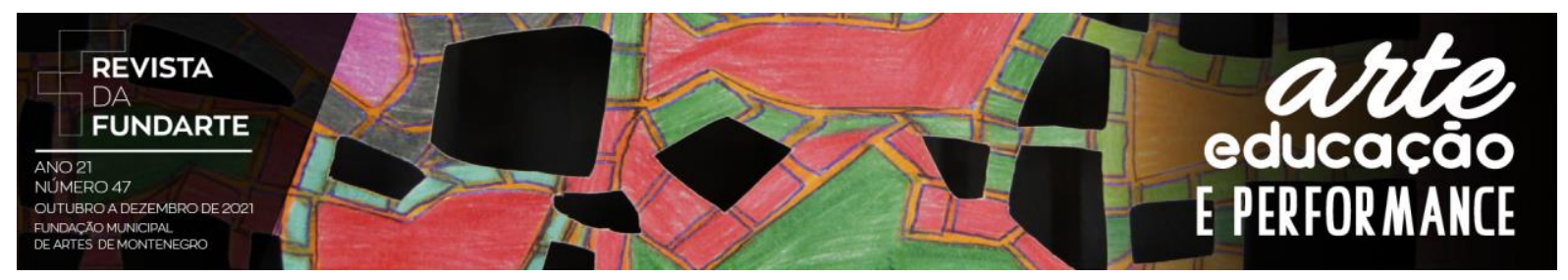

O estudo de caso examinado neste artigo foi elaborado como trabalho final para a disciplina de Desenho Infantil, ocorrida no segundo semestre de 2020, a qual abordou múltiplos aspectos do desenho infantil, tendo principalmente como base Lowenfeld e Brittain (1977), Mèredieu (2006), Derdyk (2015) e lavelberg (2006). O trabalho foi realizado por todos os discentes da disciplina, analisando produções de jovens e crianças que tinham acesso. Com a pandemia do SARS-CoV-2 (Coronavírus), o semestre de 2020/2 sofreu alteração em seu cronograma. Devido ao período de quarentena e as restrições advindas disso - especialmente a continuidade das aulas de modo remoto -, o semestre iniciou em outubro de 2020 e finalizou em abril de 2021. Também por esse motivo as análises foram feitas de forma remota, por encaminhamento do material através dos pais.

Os desenhos analisados são produções de uma menina de nove anos, que completou dez anos no decorrer da disciplina. As imagens foram enviadas por sua mãe, juntamente com uma descrição processual das produções, as quais não foram direcionadas para este estudo e tampouco provém de atividades escolares, mas sim de uma rotina de desenhos própria da criança. É perceptível em seu processo um alto nível de concentração e foco, produzindo de forma silenciosa e geralmente mais de um desenho por vez. Apesar de constantemente mostrar seus desenhos para sua mãe, o sentimento de vergonha e insuficiência já são presentes em falas sobre "não saber desenhar". Tais comentários são expostos por Lowenfeld e Brittain (1977) como características de fases que abrangem a adolescência, mas são perfeitamente elucidados por Costa, conforme o trecho abaixo:

Tanto devido à orientação defeituosa do ensino do desenho nos cursos primários, como devido mesmo à crise na idade, porque, então, esses novos adolescentes, atormentados pelas críticas importunas e inábeis dos mais velhos, já perderam a confiança neles mesmos e naquele seu mundo imaginário onde tudo era possível e tinha explicação: sentem-se inseguros, acham os desenhos que fazem ridículos, têm medo de "errar"." (COSTA, 1940 apud IAVELBERG, 2006, p. 14).

Lowenfeld e Brittain (1977) foram a referência bibliográfica base para a análise dos dados coletados, tanto por uma especificação maior das idades quanto por uma análise mais detalhada de cada período. Em um primeiro momento, foram 


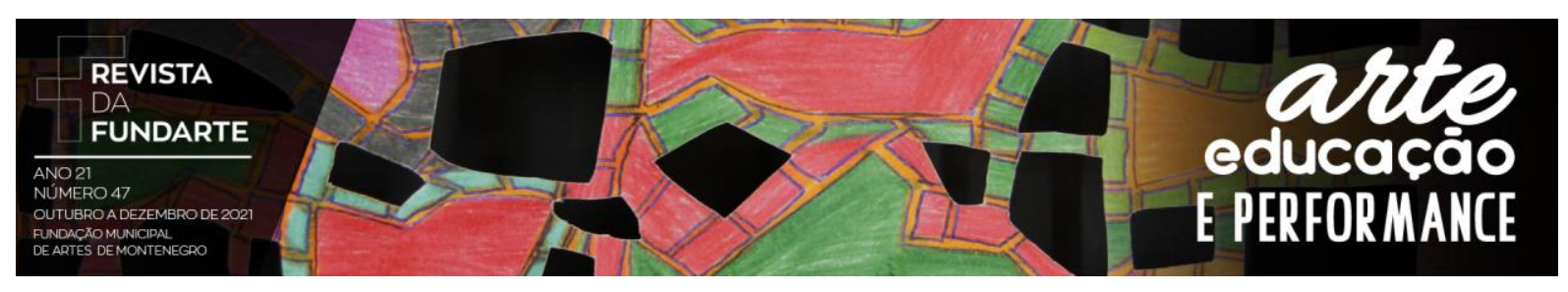

levantados questionamentos sobre a classificação por fases, sendo que nove anos é uma idade transitória entre a Fase Esquemática e a Idade da Turma.

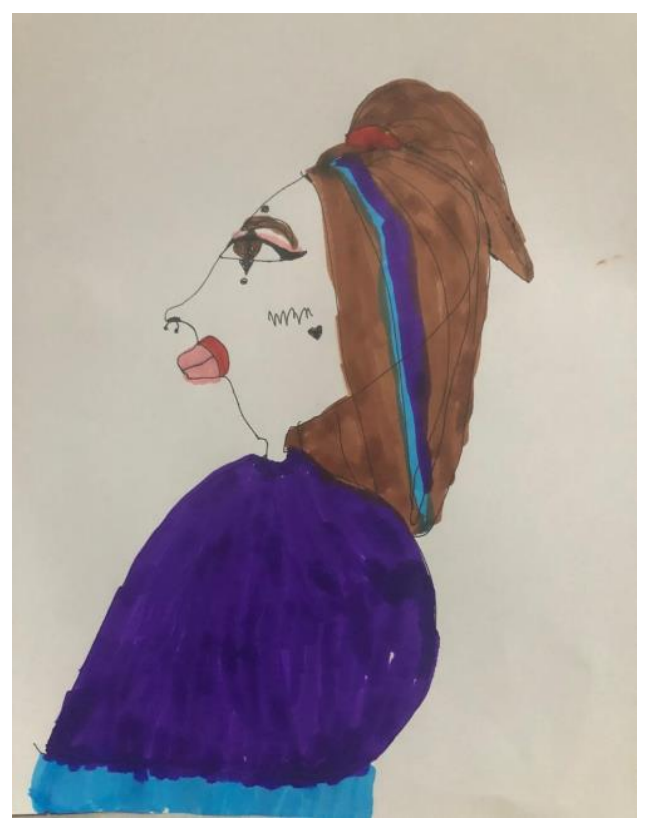

Figura 1: Desenho feito com lápis e canetinha hidrocor (dezembro/2020). Fonte: arquivo pessoal

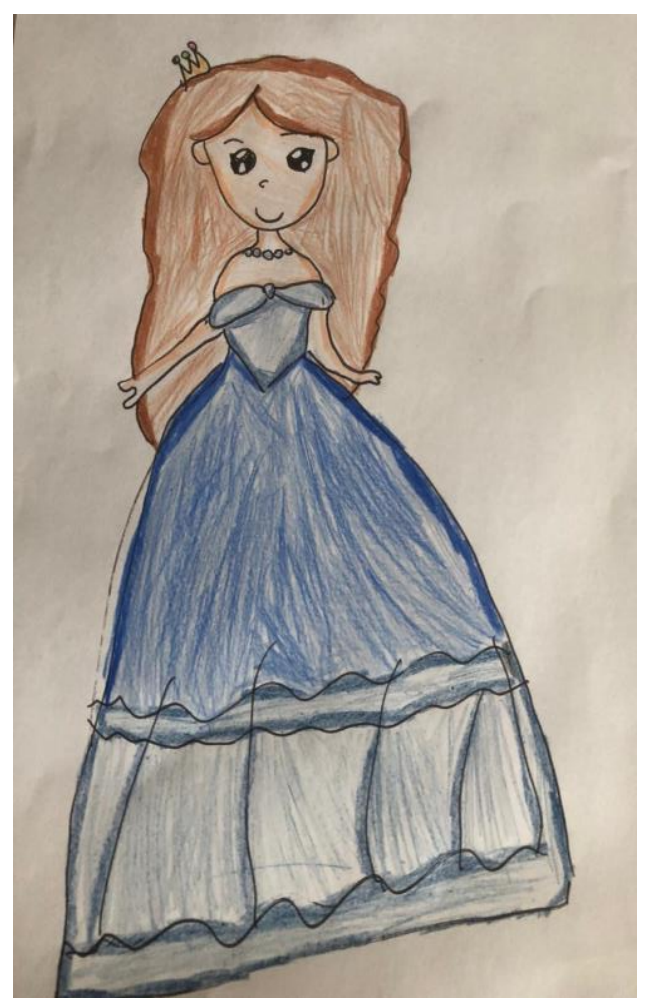

Figura 2: Desenho feito com caneta e lápis de cor (novembro/2020). Fonte: arquivo pessoal 

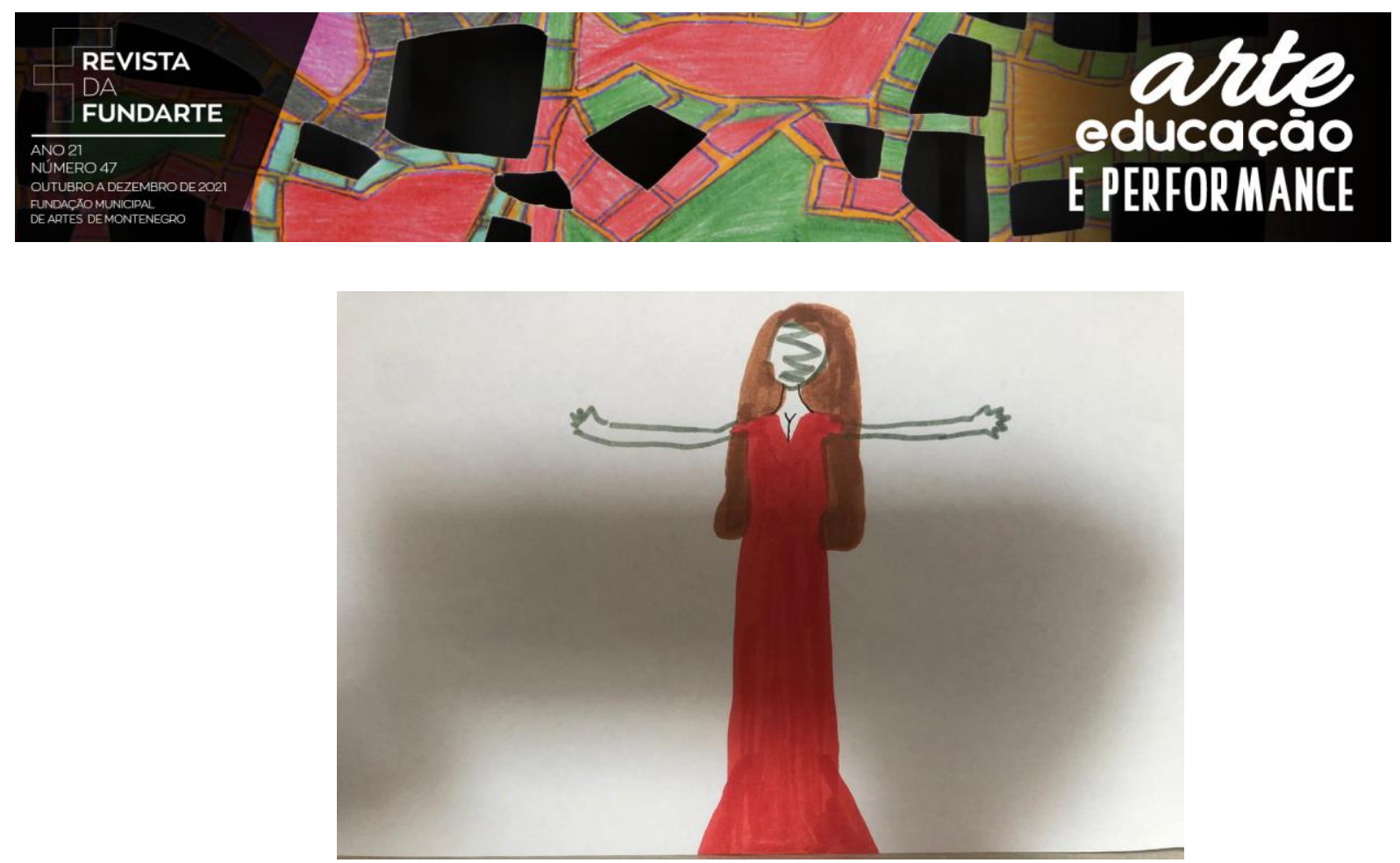

Figura 3: Desenho feito com canetinha hidrocor (dezembro/2020). Fonte: arquivo pessoal

Apesar de condizente em diversos pontos, a bibliografia utilizada não foi capaz de abranger todas as necessidades da análise, e outras afirmações de Lowenfeld e Brittain (1977) não se encontravam presentes no material coletado, como foi o caso da linha de base. Os desenhos não possuíam fundo, sendo assim não demonstravam uma descoberta de múltiplas linhas de base nem do plano. Apesar de não possuírem paisagens e raramente serem compostos por mais de um objeto, é possível perceber o uso das bordas do papel como um "chão" ou uma linha de base em alguns deles. Outra discrepância foi a ausência de desenhos de cavalo, frisado pelos autores como temática recorrente em meninas dessa idade.

O esquema puro é, para Lowenfeld e Brittain (1977) um tipo de representação que não inclui experiências intencionais, mas símbolos continuamente repetidos que definem um objeto, característica da Fase Esquemática. Na Idade da Turma, o esquema deixa de ser adequado para representar a figura humana e diferenciações de gênero começam a surgir, como vestuário e maquiagem. $O$ desenho já não é mais constituído apenas por formas geométricas, mas por símbolos que são reconhecíveis separadamente (olhos, nariz, boca), ao passo que as tentativas de representar perspectiva, luz e sombra são tímidas. São nessas inconstâncias da figura humana encontradas na coleta que podemos perceber o abandono do esquema puro, que, acompanhadas pelas 


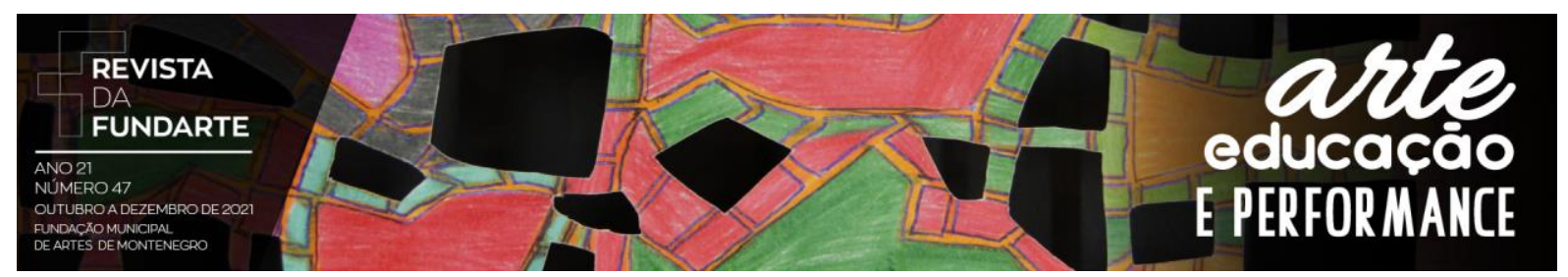

características de diferenciação de gênero, aproximam a criança pesquisada da Idade da Turma.

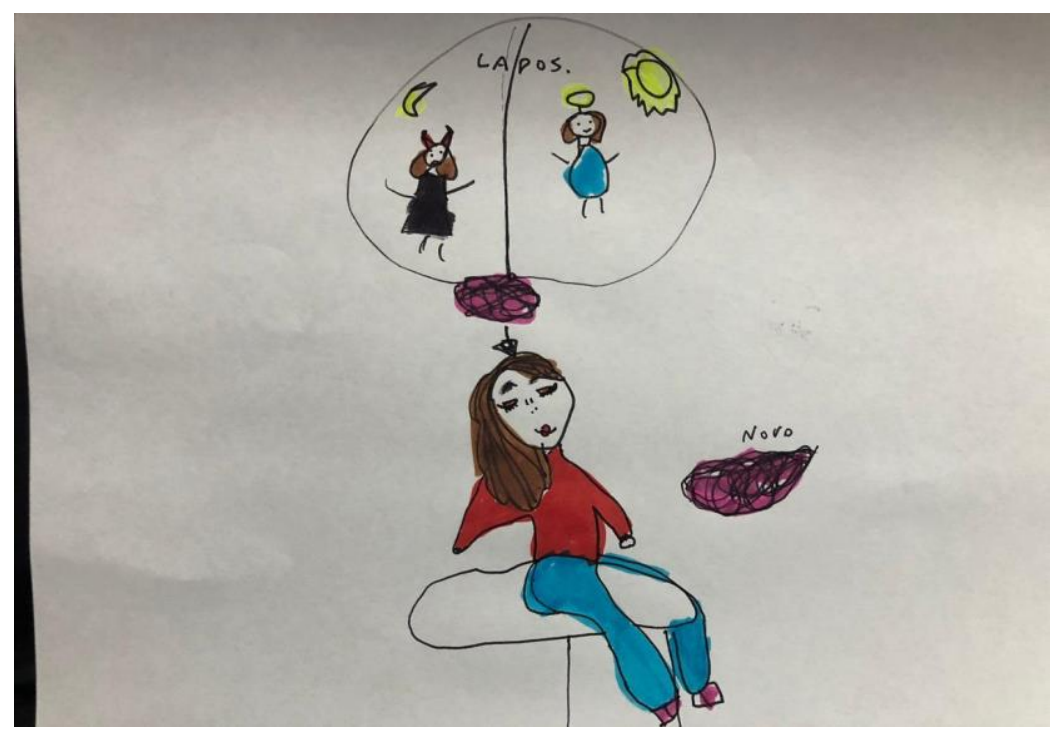

Figura 4: Desenho feito com caneta preta e canetinha hidrocor (Novembro/2020). Fonte: arquivo pessoal

Enquanto nenhum dos autores menciona a internet como influência - em virtude do período em que foram escritos - Mèredieu (2006) traz as mídias de massa como fator importante nas produções infantis. Tal pensamento continua relevante para analisarmos os impactos da internet no imaginário infantil e consequentemente em suas produções. Para além das afirmações de Mèredieu (2006), o ambiente digital, que já fazia parte do cotidiano de crianças e adolescentes, participa da vida de modo ímpar durante este período histórico da epidemia do Coronavírus, e seus reflexos na produção coletada evidenciam a influência do contexto social no desenho da criança.

A internet interfere não somente em sua rotina como também em suas produções. A participante do estudo de caso utiliza diversas redes sociais, participa de jogos online com seus amigos e atualmente tem aulas por videochamadas por conta da pandemia. A influência das mídias está presente nas maquiagens, roupas, e até mesmo na tentativa de reprodução de tutoriais e referências em seus desenhos. O Tik-tok, rede social chinesa criada em 2016, foi o aplicativo mais baixado no mundo em 2020. Apesar de aceitar apenas adolescentes acima de treze anos, é alto o número de crianças que mentem a idade ingressar na rede, como 


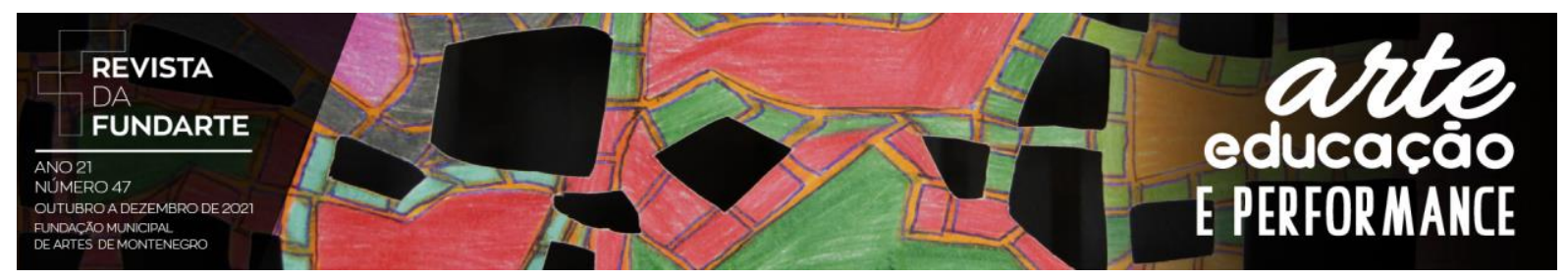

explicitado pela matéria "A necessidade de os pais monitorarem as crianças no TikTok"2. Seu conteúdo se baseia em vídeos curtos entre 15 a 60 segundos e conta com diversos tutoriais de maquiagem e de desenho, danças e tópicos de comédia, entre outros.

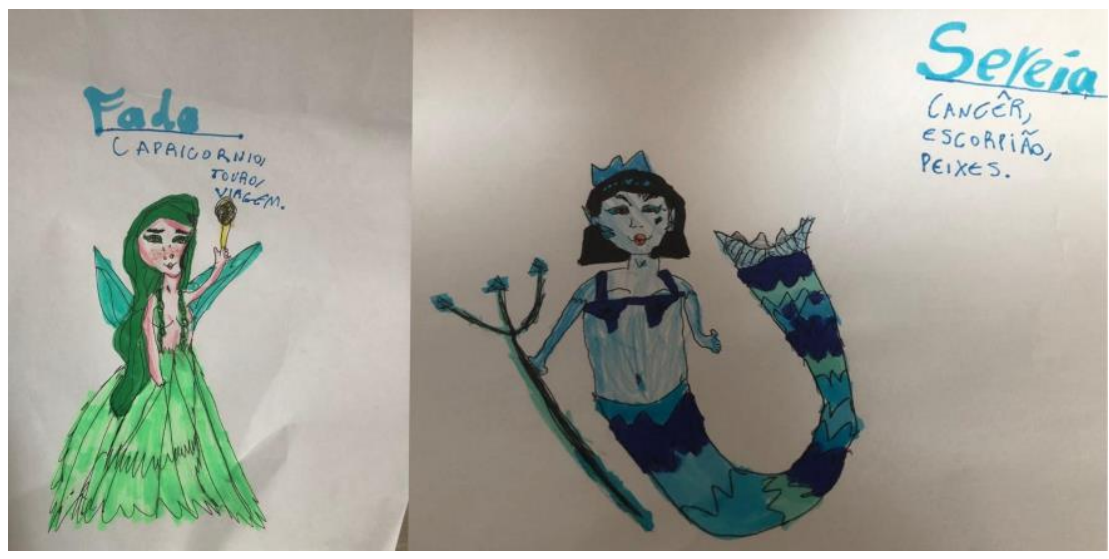

Figura 5: Desenhos feitos com caneta esferográfica, lápis de cor e canetinhas hidrocor (dezembro 2020). Fonte: arquivo pessoal

As transformações advindas da nova era, em que abundam o uso massivo da internet, fazem com que a escola dispute espaço no processo educativo com as redes sociais. Dentro das práticas pedagógicas, ideários escolanovistas apostam na ideia de que a escolarização interfere no processo natural de desenvolvimento do grafismo infantil, cerceando a criatividade espontânea da criança. Em tal premissa prepondera o protagonismo do ensino à criança, retirando do professor o papel de ensinar. Considerando que tais ideais ainda estão em prática, é correto afirmar que os estudantes buscam conteúdos educativos em outros lugares, como as redes sociais, ambiente de entretenimento e não de ensino. Nestes, incontáveis ofertas de consumo de produtos artísticos, de artistas e de processos acabam pautando a arte de forma superficial e descaracterizada. A arte, enquanto simbolização, apresenta as contradições do mundo, e seu ensino pode ajudar a educar o olhar. Compreendemos a arte como necessidade ontológica do ser humano, mas tal necessidade não emerge espontaneamente.

\footnotetext{
2 https://veja.abril.com.br/cultura/a-necessidade-dos-pais-monitorarem-as-criancas-no-tiktok/. Acesso em: 21 abr. 2021.
} 

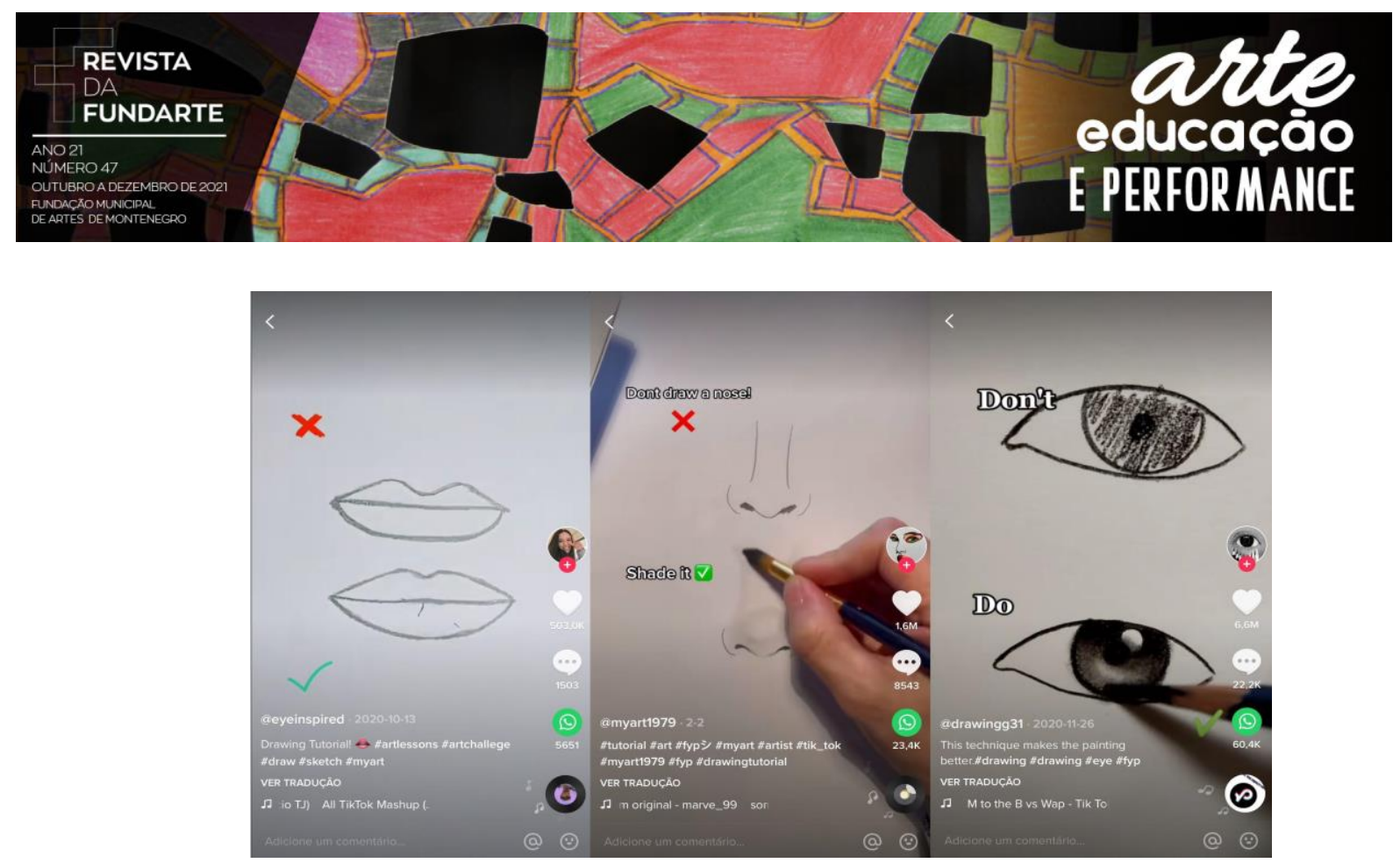

Figura 7: Tutoriais de desenho presentes na rede Tik-Tok, mostrando formas "corretas" e "erradas" de se desenhar. Fonte: @eyeinspired, @myart1979 e @drawingg31no TikTok

Apesar da idade da criança pesquisada se encontrar em uma etapa transitória para Lowenfeld e Brittain (1977), é possível perceber, após análise da coleta, que as características presentes nos desenhos a aproximam da chamada Idade da Turma. Ainda assim, é necessário salientar que as inconstâncias observadas no referencial base do estudo de caso corroboram com a visão de um desenvolvimento não linear. Dessa forma, situar a criança numa ou outra fase acarretaria seguir propostas educacionais que não são necessariamente adequadas para ela.

Mesmo sendo considerado um clássico na análise e classificação dos estágios do desenho infantil, "Desenvolvimento da capacidade criadora" - publicado originalmente em 1947 nos Estados Unidos (há mais de 70 anos) - representa um contexto singular distinto do brasileiro. Isso pode até parecer a causa das discrepâncias entre os desenhos analisados e o conteúdo teórico utilizado nesse estudo de caso, mas, para além do contexto e da data, o anacronismo da tese dos autores reside especificamente em sua base filosófica, que resvala na herança maturacionista, logrando um ideário controverso, a-histórico e não dialético.

No que tange às transformações ocorridas desde então, Langin (2018) mostra em dados essa mudança em uma pesquisa publicada no site sciencemag.org em março de 2018, apontando que, quando solicitados a desenhar 


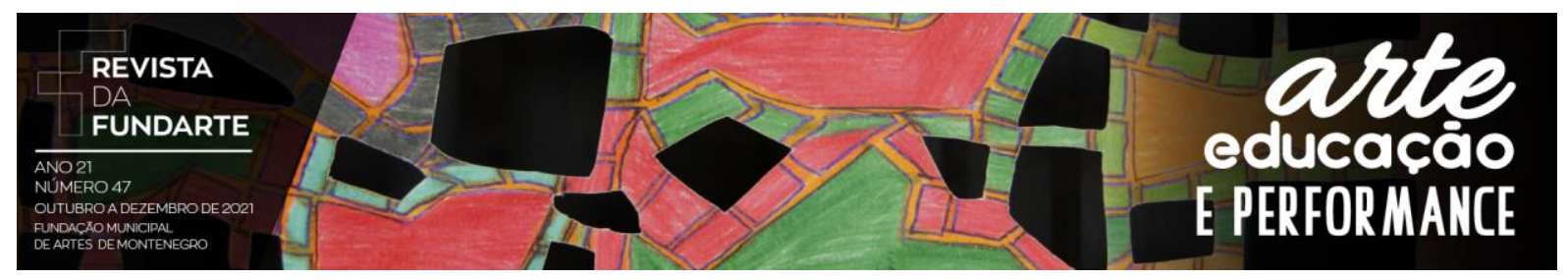

um cientista, crianças optam por fazer mulheres. Nos anos 1960 e 1970 o número de crianças que desenharam mulheres cientistas era menor que $1 \%$, chegando a $34 \%$ em 2016. Embora essas informações se restrinjam a uma pesquisa divergente da nossa, é possível assegurar que o desenho é um processo social e histórico, e seu desenvolvimento não é natural e nem espontâneo. Precisamente por isso, corroboramos com a necessidade de atualização de estudos e pesquisas nesta área para, a partir das problemáticas observadas nas referências, alargarmos as possibilidades de pensar o ensino do desenho das crianças e adolescentes na contemporaneidade.

\section{As contradições do referencial teórico sobre o desenho infantil}

Os estudos do desenho infantil, atualmente bastante presentes nas pesquisas de diversas áreas do conhecimento, tiveram seu apogeu no século XX. Iniciados ao final do século XIX - período em que a Psicologia se tornava ciência independente - as investigações ganharam relevância quando a infância passa a ser explorada ao mesmo tempo em que as ideias de Rousseau influenciavam a Pedagogia, sobretudo no que concerne às etapas do desenvolvimento gráfico da criança (MÈREDIEU, 2006).

As pesquisas sobre os aspectos próprios do grafismo infantil levaram ao reconhecimento das especificidades desse universo, especialmente no campo da Psicologia, que se debruçou a compreender a mentalidade e o desenvolvimento infantil. Georges-Henri Luquet, Arno Stern, Marthe Bernson, Liliane Lurçat, Jean Piaget, Mélanie Klein, Viktor Lowenfeld, Florence de Mèredieu, Rosa lavelberg, entre tantos outros, são alguns, dos muitos pesquisadores que contribuíram para o avanço da compreensão do grafismo infantil.

Em linhas gerais, notamos no campo do desenho infantil expressiva presença de autores cuja matriz teórica se baseia em concepções maturacionistas e etapistas do desenvolvimento. Essa premissa é válida para a pesquisa aqui evidenciada, pois em Desenho Infantil, o conteúdo do ementário é edificado sob uma perspectiva idealista. De modo amplo, as concepções em voga partem de um 


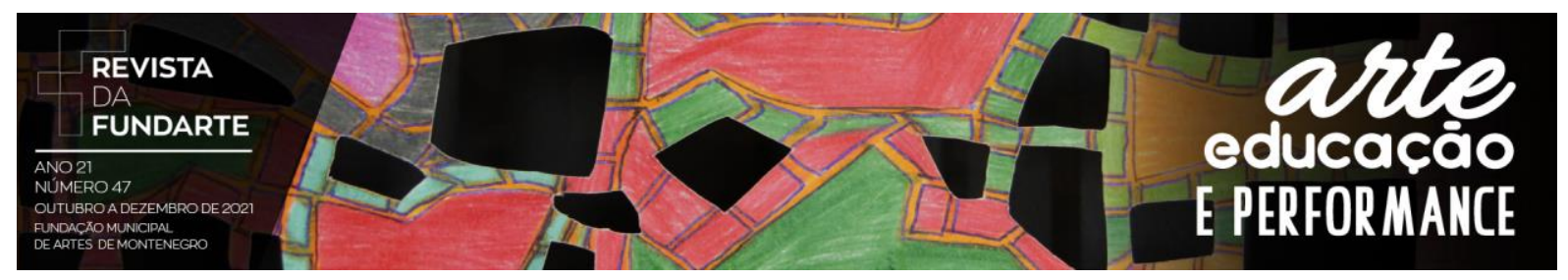

pressuposto comum: o desenvolvimento como algo natural e a perspectiva escolanovista de educação.

O desenvolvimento à ótica de Lowenfeld e Brittain (1977), Luquet (1969), lavelberg (2006) e Derdyk (2015) - autores presentes na bibliografia da disciplina -, não preconiza o ensino de Arte em si, porquanto observamos nas teses um interesse em compreender o desenho por si mesmo, muito embora num determinado momento esses autores salientem a escolarização como parte do processo de desenvolvimento. Em geral, suas obras não consistem em discutir a fundo a aprendizagem e tudo o que abarca o desenvolvimento escolar, mesmo porque situam-se em áreas distintas: psicologia, educação e arte. Ademais, a escolarização vem a ser um fator que modifica a estrutura do desenvolvimento e para muitos autores influencia negativamente no desenvolvimento da mente infantil. Deste modo, o caráter central das teorias do desenho infantil se resume em compreender os processos, o que indica direta e indiretamente a recorrência às ideias de John Dewey e o conceito de arte como experiência.

Todavia, partir dos pressupostos de um determinado autor não implica duplicar seu pensamento, mas proceder do mesmo horizonte epistemológico e filosófico. A visão idealista, compreendida como "princípio segundo o qual os problemas sociais são resultados de mentalidades errôneas, acarretando a crença de que a difusão pela educação de novas ideias entre os indivíduos, especialmente os das novas gerações, levaria à superação daqueles problemas" (DUARTE, 2010, p. 35), como por exemplo a superação da violência através da educação para a paz, ou, a resolução da destruição ambiental por meio de programas de educação ambiental, são exemplos que coadunam com o fato de desconsiderar a totalidade. Negar a totalidade significa corroborar com o princípio de realidade humana constituída por fragmentos que se unem por acontecimentos fortuitos, inacessíveis ao conhecimento racional, gerando o relativismo (epistemológico), cujo pressuposto entende o conhecimento sempre dependente do ponto de referência temporal e espacial por meio do qual o sujeito procura compreender os fenômenos naturais e sociais. Em outras palavras, não se trata de enunciar que o desenho, por exemplo, é 


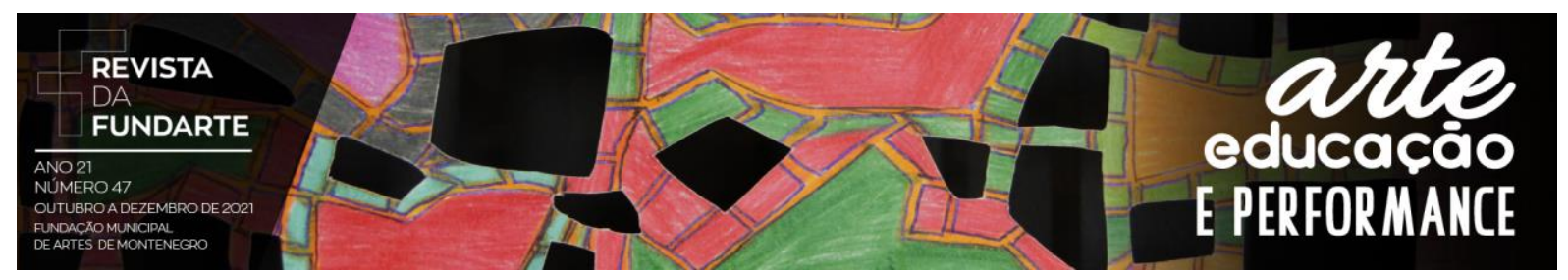

aliado ao fator cultural e social, mas entender que ao ato de conhecer é possível situar-se para além das particularidades.

Desse ideário, soma-se o princípio epistemológico pragmatista, em cuja premissa o conhecimento tem valor quando pode ser empregado para a resolução de problemas cotidianos. Duarte (2010) sublinha que o pensador pragmatista norteamericano William James em 1907 definiu a verdade como aquilo em que acreditamos ser melhor para nós. O pragmatismo também se insere em outros autores deste escopo, e é precisamente por este motivo que o mencionamos aqui, que não por acaso, impulsionou as compreensões do humano na Escola Nova. Igualmente, temos Jean Piaget, autor que, partindo da epistemologia genética, inaugurou o construtivismo. Nesta vertente epistemológica a gênese e o desenvolvimento do conhecimento humano acontecem pelo esforço de adaptação do organismo ao meio ambiente. Duarte (2010, p. 40) ao explicitar a concepção piagetiana de construtivismo destaca que:

\begin{abstract}
Os esquemas de ação e de pensamento, bem como as estruturas da inteligência desenvolvem-se movidos pela ação recíproca e complementar entre, por um lado, o esforço feito pelo sujeito cognoscente na direção da assimilação do objeto de conhecimento às suas estruturas e esquemas mentais e, por outro, a resistência que o objeto pode oferecer a essa assimilação, gerando a necessidade de reorganização espontânea dessas estruturas e esquemas mentais para que eles se acomodem às características do objeto. Do ponto de vista pedagógico, isso significa que as atividades de maior valor educativo serão aquelas que promovam esse processo espontâneo de desenvolvimento do pensamento. Nessa perspectiva não importa o que o aluno venha a saber por meio da educação escolar, mas sim o processo ativo de reinvenção do conhecimento. Aprender o conteúdo não é um fim, mas apenas um meio para a aquisição ativa e espontânea de um método de construção de conhecimentos.
\end{abstract}

Outrossim, o construtivismo também abarca um método que permite construir conhecimento por conta própria, isto é, espontaneamente. Piaget defende que aquilo que o sujeito não constrói por si, mas recebe de fora, prejudica seu processo formativo, frisando que descobrir por si é o método mais efetivo. Em conformidade a Duarte (2010, p. 41), "o mestre do construtivismo concordava com princípios pedagógicos escolanovistas" e com os métodos de trabalho em equipes, com o aprender fazendo legado por John Dewey (o learning by doing) e com a ideia 


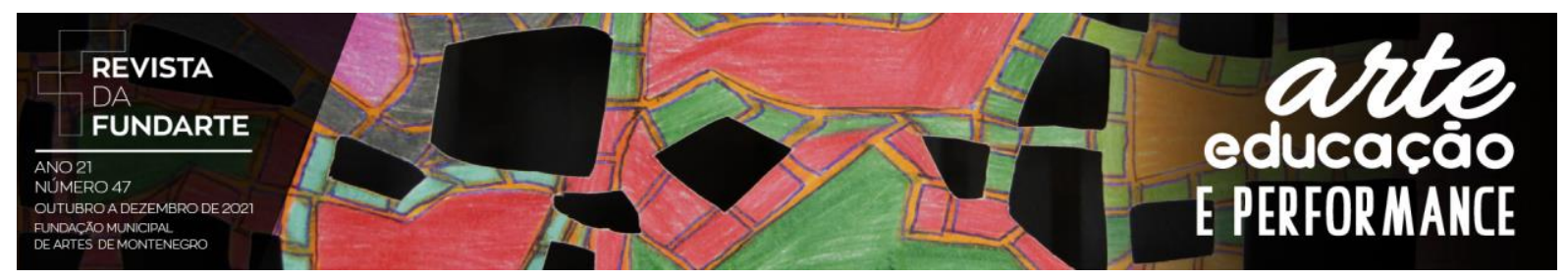

de educação funcional de Édouard Claparède. Derisso (2010) esclarece que Piaget é apontado como escolanovista porque pauta sua teoria do conhecimento e da formação da inteligência pela determinação do elemento psicológico sobre o social, fundamentando-se na ciência da psicologia genética.

Somando-se à visão fragmentária da epistemologia genética, onde há determinação do biológico sobre o social e a sociedade é entendida como agregação, há nessa teoria a recusa da realidade interferir na formação da criança, que é sujeito do conhecimento e sujeito histórico. Outro aspecto que observamos nessa herança escolanovista, presentes tanto na teoria piagetiana, quanto nos escritos de Lowenfeld e Brittain, de Rosa lavelberg, de Edith Derdyk, etc, é a compreensão da existência de necessidades naturais das crianças, além de necessidades naturais de fantasia. A gênese das necessidades é a questão decisiva nessa teoria, as quais:

[...] podem originar-se no próprio indivíduo que age ou advir do meio externo. As primeiras são entendidas como as naturais, tanto no sentido de que vêm da natureza como no sentido de que são fluidas, espontâneas, verdadeiras. As demais necessidades são entendidas como artificialidades, desdobramentos perigosos da vida civilizada. (MESQUITA, 2010, p. 75).

Nessa compreensão, quando a criança manifesta uma necessidade que não é natural, essa necessidade foi introduzida de fora, isto é, pela sociedade. $O$ retorno à natureza, das necessidades que brotam do ser, sem influências externas são formas de emanação da essência humana, ideia essa acentuada por Rousseau. Assim, há o entendimento de necessidades inatas, especialmente à criança. O contrário seriam as necessidades artificiais impostas pela escola, pelos adultos, pela sociedade em geral, necessidades essas que afastam a essência humana, segundo essa teoria. Mesquita (2010) enfatiza que os autores escolanovistas recorrem à ciência biológica para explicar o que ocasiona uma necessidade no ser:

Em última instância, eles pensam o surgimento de uma necessidade como um equilíbrio orgânico que se rompe. Esse poderia ser causado por fatores endógenos que se transformam, impulsionados pela maturação, ou por fatores exógenos como a excitação dos estímulos percebidos pelas pessoas. A atividade funcional pode ser então entendida como a busca de 


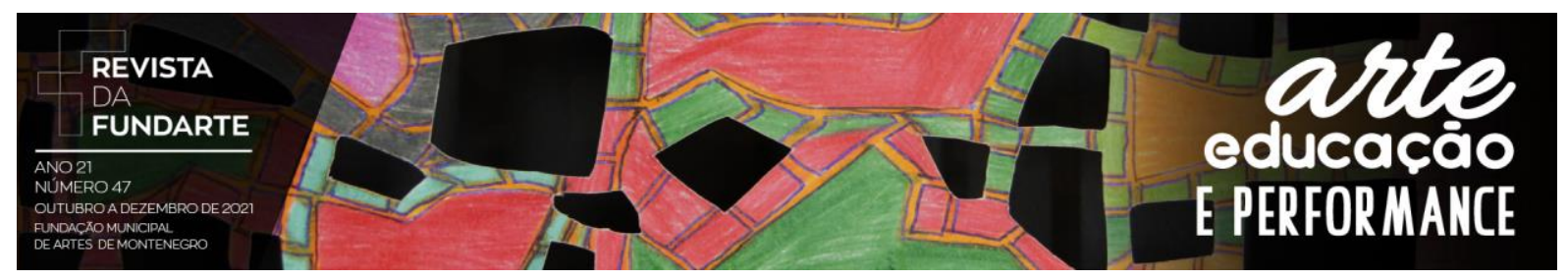

reequilibração dos organismos, pois a necessidade que a impulsiona existe em razão de um desequilíbrio interno. (MESQUITA, 2010, p. 77).

Duarte (2001) identifica e mostra que a problemática do pensamento de Piaget é a naturalização e universalização a-histórica dos seres humanos, de modo que explica os fenômenos humanos a partir das ciências naturais. A fragilidade expressa nesse pensamento pode ser observada na própria defesa da existência de necessidades puras, que surgem no ser sem nenhuma influência dos adultos e da vida social. Contrariamente, nossas necessidades são profundamente históricas. Conforme Marx e Engels (2007), a produção dos meios de satisfação das necessidades humanas é a primeira e fundamental mediação da história. De forma dialética, quando o ser humano começa a modificar a natureza, modifica também a si próprio, lembrando que o ser humano produz bens materiais, relações e instituições sociais, ideias e qualidades humanas (KOSIK, 1976), transformando as circunstâncias de sua vida e ao mesmo tempo sendo constituído por elas de forma consciente. Mesquita (2010, p. 79) sublinha que "não podem existir circunstâncias sociais ou necessidades que não possuam raízes na história do homem sobre a Terra". Da mesma forma, as necessidades humanas se constituem não somente no aqui e no agora, mas de uma influência social que sintetiza passado e presente.

Mesquita (2010) rememora o que D. Elkonin - psicólogo soviético expressa quanto ao desenvolvimento das necessidades, enunciando que essas iniciam desde a mais tenra idade, devido a três fatores inseparáveis: nossa própria atividade, o convívio com os demais seres humanos e os objetos da cultura. Necessidades não surgem apartadas da vida real da criança, e, ainda, são conexas a uma relação psicológica especialmente voltada aos adultos. "Não pode haver necessidade humana sem atividade, história, cultura e sociedade" (MESQUITA, 2010, p. 80); não pode, portanto, haver necessidade naturalmente.

Para nos encaminharmos ao final do debate, um último aspecto precisa ser elucidado, o qual corresponde ao ensino artístico nessa perspectiva piagetiana e escolanovista - e, portanto, naturalizante e idealista - ser caracterizado como algo que deve interferir minimamente no desenvolvimento gráfico das crianças. Neste ângulo, o professor acompanha, favorece e estimula; em outras palavras, o 


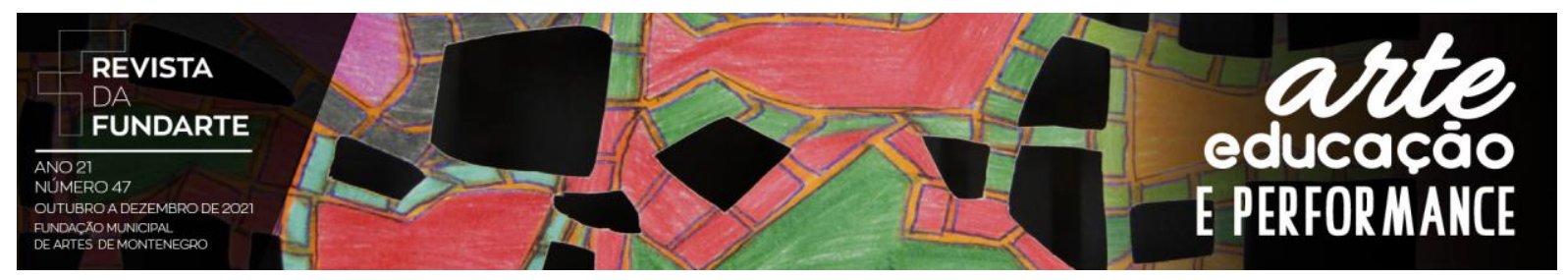

processo natural de desenvolvimento gráfico das crianças deve desabrochar com ínfima intervenção do adulto e da sociedade, já que o que a criança precisa para se desenvolver já está nela, basta ofertar mecanismos, recursos e condições para que aconteça, preponderando a ideia de que o ensino de Arte adequado à estimulação gráfica é o que oferta variedade de materiais, proposições e circunstâncias, desde que apropriados à idade e aos pressupostos da etapa do desenvolvimento.

\section{Considerações finais}

A despeito das problemáticas pautadas ao longo deste texto, não é excesso esclarecer que o estudo se propôs a discuti-las no intuito de descortinar as contradições mais presentes, sobretudo porque os estudos do desenho infantil são praticados, no caso da Licenciatura em Artes Visuais, na formação inicial e se estendem à atuação profissional. Há muitas premissas que circundam os discursos, que eventualmente carecem de maiores e mais profundas elaborações teóricas, uma vez que notamos a abundância de áreas que se debruçam sobre o tema e que podem gerar perigoso ecletismo na compreensão filosófica de tais teorias. Em outras palavras, há que se analisar as particularidades e as múltiplas determinações do fenômeno, isto é, do grafismo infantil. Se o isolarmos, recairemos no vício de analisá-lo superficialmente.

Tendo em vista que os autores do desenho infantil concordam que as crianças garatujam, classificá-lo por fases parece uma tarefa certeira. Porém, as inconstâncias no desenvolvimento da adolescência e pré-adolescência e seus contextos sociais/culturais/econômicos, tornam o estudo dessa etapa mais complexo e imprevisível. É possível observar na produção coletada no estudo de caso um exemplo de tais variáveis: a influência da internet. As maquiagens, roupas, e até mesmo a tentativa de reprodução de tutoriais e referências presentes nas redes sociais afetam a produção e podem inflamar a formação da crise da idade, já exposta anteriormente. Os tutoriais que visam ensinar a desenhar fazem um desserviço aos educadores de Arte e às crianças e adolescentes expostos a esse conteúdo que tem por objetivo os acessos, e não a educação em si. 


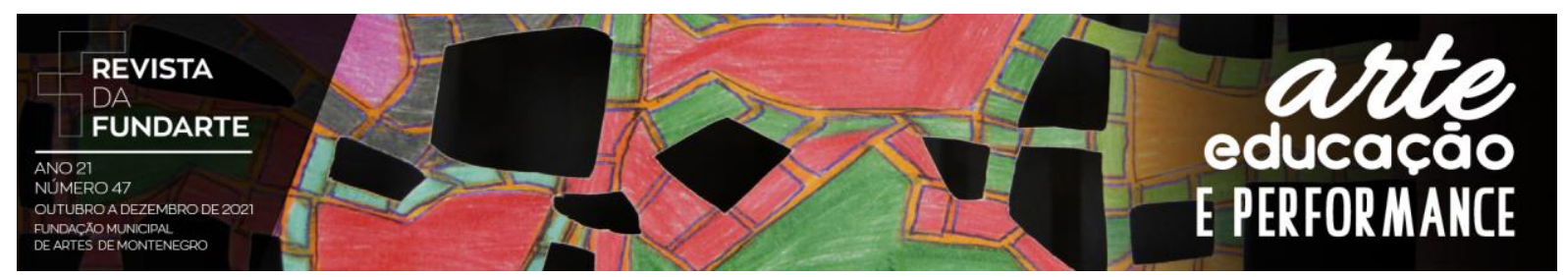

Este é um estudo que fornece pistas para questionarmos as possibilidades de analisar o desenho de crianças e adolescentes em tempos distintos em que as teorias foram elaboradas. Ora, se há gigantescas lacunas nos dados coletados para o estudo de caso (trabalho final da disciplina de Desenho Infantil), logo, a própria contradição teórica fica em evidência: não é sobre o lócus temporal que, por exemplo, meninas brasileiras não desenham necessariamente cavalos, como propunha Lowenfeld e Brittain (1977), ou que a linha de base sequer aparece, mas trata-se precisamente de validar que o desenvolvimento não é linear, tampouco natural e que a diferenciação de características que, em tese, seriam próprias das etapas do grafismo, não desapareceram porque os costumes e épocas mudaram, mas que dependem (muito) do fator social. Desta feita, o referencial teórico para o estudo de caso talvez tenha sido insuficiente às premissas contemporâneas, mas por outro lado, garantiu a abertura para questionarmos à própria discussão em torno do grafismo nas diversas esferas do desenvolvimento, trazendo-os à luz e suscitando novas análises.

\section{Referências:}

BARROS, Maria Eduarda; SAMPAIO, Jana. A necessidade dos pais monitorarem as crianças no TikTok. 2021. Disponível em: https://veja.abril.com.br/cultura/anecessidade-dos-pais-monitorarem-as-criancas-no-tiktok/. Acesso em: 21 abr. 2021.

BRASIL, Ministério da Saúde. Proteger e Cuidar da Saúde de Adolescentes na Atenção Básica. 2. ed. Brasília: Ministério da Saúde, 2018. Disponível em: http://bvsms.saude.gov.br/bvs/publicacoes/proteger_cuidar_adolescentes_atencao_ basica_2ed.pdf. Acesso em: 30 abr. 2021.

DERDYK, Edith. Formas de pensar o desenho: o desenvolvimento do grafismo infantil. Porto Alegre: Zouk, 2015

DERISSO, José Luis. Construtivismo, pós-modernidade e decadência ideológica. In: In: MARTINS, Lígia Márcia, DUARTE, Newton (orgs.). Formação de professores: limites contemporâneos e alternativas necessárias [online]. São Paulo: Editora UNESP; São Paulo: Cultura Acadêmica, 2010. 191 p. ISBN 978-85-7983-103-4. Disponível em: http://books.scielo.org/id/ysnm8/pdf/martins-9788579831034.pdf. Acesso em: 05 set. 2021. 


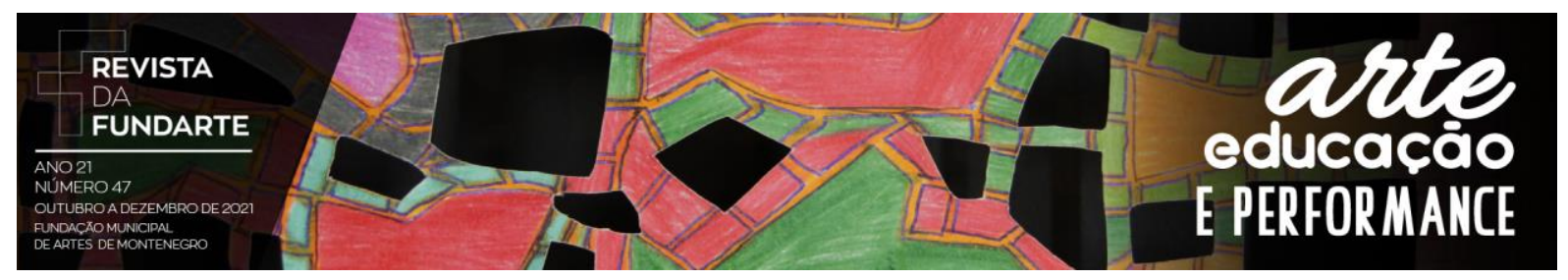

DUARTE, Newton. O debate contemporâneo das teorias pedagógicas. In: MARTINS, Lígia Márcia, DUARTE, Newton (orgs.). Formação de professores: limites contemporâneos e alternativas necessárias [online]. São Paulo: Editora UNESP; São Paulo: Cultura Acadêmica, 2010. 191 p. ISBN 978-85-7983-103-4. Disponível em: http://books.scielo.org/id/ysnm8/pdf/martins-9788579831034.pdf. Acesso em: 04 set. 2021.

DUARTE, Newton. Vigotski e o aprender a aprender: crítica as apropriações neoliberais e pós-modernas da teoria vigotskiana. Campinas, SP: Autores Associados, 2001.

IAVELBERG, Rosa. O desenho cultivado da criança: prática e formação de educadores. Porto Alegre: Zouk, 2006.

KOSIK, Karel. A dialética do concreto. Rio de Janeiro: Paz e Terra, 1976.

LANGIN, Katie. What does a scientist look like? Children are drawing women more than ever before. 2018.2 Disponível em: https://www.sciencemag.org/news/2018/03/what-does-scientist-look-children-aredrawing-women-more-ever. Acesso em: 01 mar. 2021.

LOWENFELD, Viktor. BRITTAIN, W.L. Desenvolvimento da capacidade criadora. São Paulo: Mestre Jou, 1977.

LUQUET, G. H. O Desenho Infantil. Porto: Companhia Editora do Minho, 1969.

MARX, Karl. ENGELS, Friedrich. A ideologia alemã. São Paulo: Boitempo, 2007.

MÈREDIEU, Florence de. O desenho infantil. São Paulo: Cultrix, 2006.

MESQUITA, Afonso Mancuso. Os conceitos de atividade e necessidade para a Escola Nova e suas implicações para a formação de professores. In: MARTINS, Lígia Márcia, DUARTE, Newton (orgs.). Formação de professores: limites contemporâneos e alternativas necessárias [online]. São Paulo: Editora UNESP; São Paulo: Cultura Acadêmica, 2010. 191 p. ISBN 978-85-7983-103-4. Disponível em: http://books.scielo.org/id/ysnm8/pdf/martins-9788579831034.pdf. Acesso em: 05 set. 2021. 